\title{
AVALIAÇÃO DA INFLUÊNCIA DA COMPOSIÇÃO MINERALÓGICA NO CONSUMO ENERGÉTICO NA PRODUÇÃO DE LIGAS DE MANGANES*
}

Sergio Trindade ${ }^{1}$ Anderson Alves Cunha

\section{Resumo}

O elevado consumo de energia elétrica no processo de fabricação de ligas de manganês, associado a uma baixa disponibilidade deste recurso no Brasil, justifica a busca por processos mais eficientes que promovam o aumento da competitividade e sustentabilidade do negócio. O presente trabalho teve como objetivo quantificar o consumo de energia elétrica, na produção de ligas de manganês, em função da composição mineralógica da carga de alimentação no forno elétrico a arco. A metodologia adotada consistiu de quatro etapas básicas: revisão bibliográfica da caracterização mineralógica e química dos minérios de manganês utilizados no processo, levantamento do histórico de produção em função do consumo de energia e proporção de minérios na carga metálica de alimentação do reator, tratamento e discussão dos dados e, por último, elaboração do artigo. Os resultados permitiram identificar uma ordem a priorizar na alimentação dos minérios com melhores performance de processo. Os minérios são, na ordem do melhor para o pior, minério de manganês de Carajás (Azul), minério de manganês de Urucum e o minério de manganês Sílico Carbonatado (Morro da Mina).

Palavras-chave: Minério de manganês; Mineralogia; Forno elétrico a arco.

\section{MINERALOGICAL COMPOSITION OF INFLUENCE ASSESMENT ON ENERGY CONSUMPTION IN MANGANESE ALLOY PRODUCTION}

\section{Abstract}

The high consumption of electricity in manganese alloy manufacturing process, combined with a low availability of this resource in Brazil, justifies the search for more efficient processes that promote increased competitiveness and sustainability of the business. This study aimed to quantify the electricity consumption in the production of manganese alloys, depending on the mineralogical composition of the feedstock in electric arc furnaces. The methodology consisted of four basic steps: literature review of the mineralogical and chemical characterization of manganese ores used in the process, raising the production history in terms of energy consumption and proportion of minerals in the feed metal loading in the reactor, treatment and discussion data and, finally, preparation of the article. The results showed an order to prioritize the supply of minerals with better process performance. The ores are in the best order for the worse, Carajás manganese ore (Azul), Urucum manganese ore and Carbonatado Sílico manganese ore (Morro da Mina).

Keywords: Manganese ore; Mineralogy; Eletric arc furnace.

1 Graduando em Engenharia Metalúrgica, Técnico da Vale, Faculdade Santa Rita, Conselheiro Lafaiete, Minas Gerais. Brasil.

2 Engenheiro Metalurgista, MSc, Professor, Departamento de Engenharia Metalúrgica, Faculdade Santa Rita, Conselheiro Lafaiete, Minas Gerais. Brasil. 


\section{INTRODUÇÃO}

De acordo com Olsen et al. [1] o manganês é um metal comum na crosta terrestre, com concentração de quase $0,1 \%$, sendo o décimo segundo elemento mais abundante na crosta terrestre e o quarto metal com maior uso comercial. Pertence a família dos metais de transição com massa atômica 54,938u, número atômico 25 e símbolo Mn. Puro é um elemento metálico, com densidade específica entre 7,21 e $7,44 \mathrm{Kg} / \mathrm{dm}^{3}$, variando conforme sua forma alotrópica e possui coloração branca acinzentada, semelhante ao ferro, porém possui maior dureza e maior fragilidade. Seu ponto de fusão é $1244^{\circ} \mathrm{C}$ e de ebulição $2060^{\circ} \mathrm{C}$.

Existem diversos minerais que contem manganês, porém poucos são considerados minérios devido ao teor. Olsen et al. [1] classificou os minérios de manganês em três classes de acordo com os seus teores: minérios metalúrgicos, contendo mais de $35 \%$ de manganês; minérios ferruginosos, contendo de 15 a $35 \%$ de manganês e elevados teores de ferro; minérios manganesíferos, composto essencialmente por minérios de ferro com 5 a 10\% de manganês. Os principais depósitos de minérios de manganês no Brasil estão localizados no estado do Mato Grosso do Sul, Pará e Minas Gerais.

No Mato Grosso do Sul, na cidade de Corumbá, localiza o depósito de Urucum que possui um dos melhores minérios de manganês do mundo, com teores médios de $45 \%$ de manganês. Os minérios extraídos são classificados em dois: Standard, com teor de fósforo acima de $0,12 \%$, e o Baixo Fósforo, com teor de fósforo abaixo de $0,12 \%$ [2]. No Pará, no município de Parauapebas, localiza a mina do Azul que é a maior produtora de minério de manganês do Brasil e da América Latina. $O$ minério de Azul é conhecido como minério de manganês Carajás e é composto majoritariamente por óxidos, com teor entre 46 a 47\% de Mn [2]. Em Minas Gerais, na cidade de Conselheiro Lafaiete, localiza a mina de Morro da Mina que possui em média $30 \%$ de Mn e seus principais constituintes são carbono-silicatos, denominado de minério Sílico Carbonatado ou Morro da Mina [2]. Os três minérios e a mineração Morro da Mina estão demonstrados na figura 1.

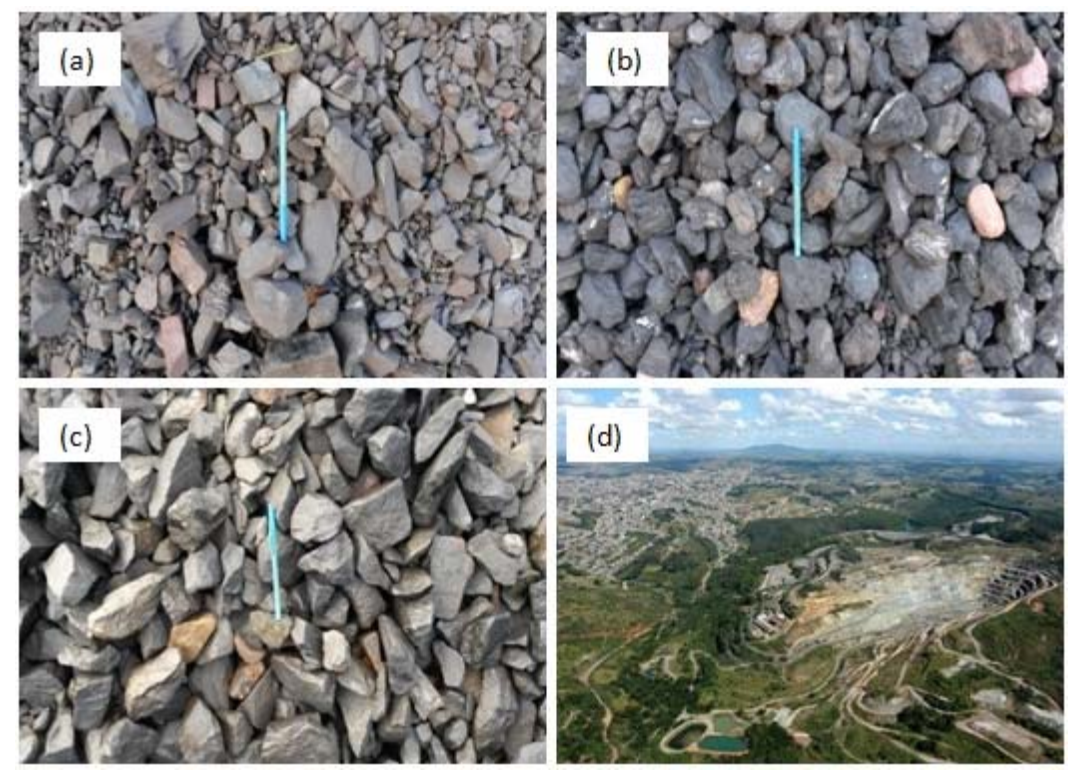

Figura 1. (a) minério de manganês de Urucum (b) minério de manganês de Carajás (Azul) (c) minério de manganês Sílico Carbonatado ou Morro da Mina (d) Mineração Morro da Mina, Conselheiro Lafaiete - MG. 
1.1 Identificação de fases por meio da técnica de Difratometria de Raios $X$ (VALE, 2014) [2].

As principais fases identificadas nos três minérios (Azul ou Carajás, Urucum e Morro da Mina ou Sílico Carbonatado) estão apresentadas na tabela 1. No minério de Azul, as fases portadoras de manganês são a Criptomelana, Pirolusita, Birnessita e Todorokita. No minério de Urucum as fases são a Criptomelana e Pirolusita e no minério do Morro da Mina, são a Rodocrosita, Espessartita e Trefoíta.

Tabela 1.Identificação de fases presentes nos minérios Azul (Carajás), Urucum e Morro da Mina (minério Sílico Carbonatado) [3]

\begin{tabular}{|c|c|c|c|c|}
\hline \multicolumn{2}{|c|}{ Fases identificadas } & Azul & Urucum & M. Mina \\
\hline Criptomelana & $\mathrm{K}\left(\mathrm{Mn}^{4+}, \mathrm{Mn}^{2+}\right)_{8} \mathrm{O}_{16}$ & + & + & \\
\hline Pirolusita & $\mathrm{Mn}^{4+} \mathrm{O}_{2}$ & + & + & \\
\hline Birnessita & $\begin{array}{l}(\mathrm{Na}, \mathrm{Ca}, \mathrm{K})\left(\mathrm{Mn}^{4+}\right. \\
\left.\mathrm{Mn}^{3+}\right)_{2} \mathrm{O}_{4} \cdot 1,5 \mathrm{H}_{2} \mathrm{O}\end{array}$ & + & & \\
\hline Todorokita & $\begin{array}{l}\left(\mathrm{Ca}, \mathrm{K}, \mathrm{Na}, \mathrm{Mg}, \mathrm{Ba}, \mathrm{Mn}^{2+}\right)\left(\mathrm{Mn}^{4+},\right. \\
\left.\mathrm{Mn}^{2+}, \mathrm{Mg}, \mathrm{Al}\right)_{6} \mathrm{O}_{12} \cdot 3 \mathrm{H}_{2} \mathrm{O}\end{array}$ & + & & \\
\hline Braunita & $\mathrm{Mn}^{2+} \mathrm{Mn}^{3+}{ }_{6} \mathrm{SiO}_{12}$ & & + & \\
\hline Rodocrosita & $\mathrm{Mn}^{2+} \mathrm{CO}_{3}$ & & & + \\
\hline Rondonita & $\mathrm{Mn}^{2+} \mathrm{SiO}_{3}$ & & & \\
\hline Quartzo & $\mathrm{SiO}_{2}$ & + & + & + \\
\hline Gibbsita & $\mathrm{Al}(\mathrm{OH})_{3}$ & + & & \\
\hline Hematita & $\mathrm{Fe}_{2} \mathrm{O}_{3}$ & & + & \\
\hline Espessartita & $\mathrm{Mn}^{2+}{ }_{3} \mathrm{Al}_{2}\left(\mathrm{SiO}_{4}\right)_{3}$ & & & + \\
\hline Trefoíta & $\mathrm{Mn}_{2}^{2+} \mathrm{SiO}_{4}$ & & & + \\
\hline Flogopita & $\mathrm{KMg}_{3}\left(\mathrm{AlSi}_{3} \mathrm{O}_{10}\right)(\mathrm{OH}, \mathrm{F})_{2}$ & & & + \\
\hline Cumingtonita* & $\mathrm{Fe}_{2} \mathrm{Mg}_{5} \mathrm{Si}_{8} \mathrm{O}_{22}(\mathrm{OH})_{2}$ & & & + \\
\hline Pargasita* & $\begin{array}{l}\mathrm{NaCa}_{2}(\mathrm{Mg}, \mathrm{Fe})_{4} \mathrm{Al}\left(\mathrm{Si}_{6} \mathrm{Al}_{2}\right) \mathrm{O}_{22} \\
(\mathrm{OH})_{2}\end{array}$ & & & + \\
\hline Albita & $\mathrm{NaAlSi}_{3} \mathrm{O}_{8}$ & & & + \\
\hline Faialita* & $\mathrm{Fe}_{2} \mathrm{SiO}_{4}$ & & & + \\
\hline
\end{tabular}

\subsection{Caracterização mineralógica e química dos principais minérios de mangnês do Brasil realizados por FARIA, 2011 [2].}

As tabelas 2, 3 e 4 contém os resultados das análises mineralógicas por microscopia óptica e das análises químicas das amostras. De acordo com Faria [2] o minério de manganês Urucum é composto principalmente por Criptomelana e Pirolusita. Segundo Faria [2] a criptomelana está disposta numa textura laminada rítmica, formada por lâminas ricas em microporosidade e lâminas maciças. O teor de 13,85\% de ferro desse minério é devido, principalmente, ao conteúdo de hematita presente. A caracterização do minério de Urucum é mostrado na tabela 2. 
Tabela 2 . Caracterização mineralógica e química do minério de Urucum [2]

\begin{tabular}{|c|c|c|c|c|c|c|c|c|}
\hline \multirow{3}{*}{ 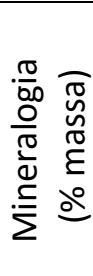 } & \multicolumn{8}{|c|}{ Constituintes } \\
\hline & \multicolumn{2}{|c|}{$\begin{array}{c}\mathrm{KMn}_{8} \mathrm{O}_{16} \\
\text { (Criptomelana) } \\
\mathrm{MnO}_{2} \text { (Pirolusita) }\end{array}$} & $\begin{array}{c}\mathrm{Mn}_{6} \mathrm{SiO}_{12} \\
\text { (Braunita) }\end{array}$ & \multicolumn{2}{|c|}{$\begin{array}{c}\mathrm{Fe}_{2} \mathrm{O}_{3} \\
\text { (Hematita }\end{array}$} & \multicolumn{2}{|c|}{$\begin{array}{c}\mathrm{FeO} . \mathrm{OH} \\
\text { (Goethita) }\end{array}$} & Outros \\
\hline & \multicolumn{2}{|c|}{$65-55$} & $30-20$ & \multicolumn{2}{|c|}{$16-12$} & \multicolumn{2}{|c|}{$3-1$} & $3-2$ \\
\hline \multirow{3}{*}{ 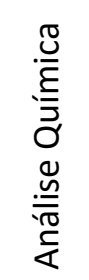 } & \multicolumn{8}{|c|}{ Elementos / Compostos (\%) } \\
\hline & $\mathrm{Mn}$ & $\mathrm{Fe}$ & $\mathrm{SiO}_{2}$ & $\mathrm{P}$ & $\mathrm{A}_{12} \mathrm{O}_{3}$ & $\mathrm{CaO}$ & $\mathrm{MgO}$ & $\mathrm{TiO}_{2}$ \\
\hline & 42,69 & 13,85 & 5,67 & 0,29 & 2,74 & 0,290 & 0,150 & 0,020 \\
\hline
\end{tabular}

O minério de manganês Carajás ou azul apresenta o maior teor de manganês entre os três minérios e sua composição mineralógica majoritária é constituída de Criptomelana, Todorokita, N-sutita e Gibbsita. De maneira diferente do minério de Urucum, o conteúdo de ferro é proveniente da magnetita [2]. A caracterização do minério de Carajás é apresentado na tabela 3.

Tabela 3 . Caracterização mineralógica e química do minério de Carajás [2]

\begin{tabular}{|c|c|c|c|c|c|c|c|c|c|c|}
\hline \multirow{3}{*}{ 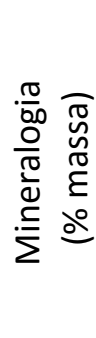 } & \multicolumn{8}{|c|}{ Constituintes } & \multirow[b]{2}{*}{$\begin{array}{c}\mathrm{Fe}_{3} \mathrm{O}_{4} \\
\text { (Magnetita) }\end{array}$} & \multirow[b]{2}{*}{ 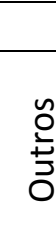 } \\
\hline & \multicolumn{2}{|c|}{$\begin{array}{c}\mathrm{KMn}_{8} \mathrm{O}_{16} \\
\text { (Criptomelana) }\end{array}$} & $\begin{array}{c}(\mathrm{Na}, \mathrm{Ca}, \mathrm{K})_{2} \\
\mathrm{Mn}_{6} \mathrm{O}_{12} .3 \mathrm{a} \\
4,5\left(\mathrm{H}_{2} \mathrm{O}\right) \\
\text { Todorokita }\end{array}$ & $\begin{array}{c}\mathrm{Mn}(\mathrm{O} . \mathrm{OH})_{2} \\
\text { (N-sutita) }\end{array}$ & \multicolumn{2}{|c|}{$\begin{array}{c}\mathrm{Al}(\mathrm{OH})_{3} \\
\text { (Gibbsita) }\end{array}$} & \multicolumn{2}{|c|}{$\begin{array}{c}\mathrm{MnO}_{2} \\
\text { (Pirolusita) }\end{array}$} & & \\
\hline & \multicolumn{2}{|c|}{$33-23$} & $33-23$ & $16-10$ & \multicolumn{2}{|c|}{$13-10$} & \multicolumn{2}{|c|}{$4-2$} & $7-5$ & $\begin{array}{c}8- \\
7\end{array}$ \\
\hline \multirow{3}{*}{ 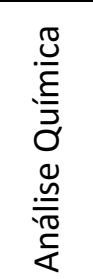 } & \multicolumn{10}{|c|}{ Elementos / Compostos (\%) } \\
\hline & $\mathrm{Mn}$ & $\mathrm{Fe}$ & $\mathrm{SiO}_{2}$ & $\mathrm{P}$ & $\mathrm{A}_{12} \mathrm{O}_{3}$ & & $\mathrm{O}$ & $\mathrm{MgO}$ & \multicolumn{2}{|l|}{$\mathrm{TiO}_{2}$} \\
\hline & 47,68 & 3,59 & 3,16 & 0,097 & 5,22 & & 20 & 0,180 & \multicolumn{2}{|c|}{0,240} \\
\hline
\end{tabular}

O minério de manganês Sílico Carbonatado (Morro da Mina), apresenta o mais baixo teor de manganês $(28,44 \% \mathrm{Mn})$ entre os três minérios e maiores teores de quartzo $\left(24,59 \% \mathrm{SiO}_{2}\right)$ e alumina $\left(7,77 \% \mathrm{Al}_{2} \mathrm{O}_{3}\right)$. A composição mineralógica majoritária é composto por Rodocrosita, Espessarita e Tefroíta [2]. 
Tabela 4 . Caracterização mineralógica e química do minério de manganês Sílico Carbonatado (Morro da Mina) [2]

\begin{tabular}{|c|c|c|c|c|c|c|c|c|c|}
\hline \multirow{3}{*}{ 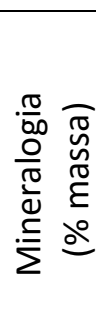 } & \multicolumn{8}{|c|}{ Constituintes } & \multirow[b]{2}{*}{ Outros } \\
\hline & \multicolumn{2}{|c|}{$\begin{array}{c}\mathrm{MnCO}_{3} \\
\text { (Rodocrosita) }\end{array}$} & \multicolumn{2}{|c|}{$\begin{array}{l}\mathrm{Mn}_{3} \mathrm{Al}_{2}\left(\mathrm{SiO}_{4}\right)_{3} \\
\text { (Espessartita) }\end{array}$} & \multicolumn{2}{|c|}{$\begin{array}{c}\mathrm{Mn}_{2} \mathrm{SiO}_{4} \\
\text { (Tefroíta) }\end{array}$} & $\begin{array}{c}(\mathrm{Fe}, \mathrm{Mg})_{2} \mathrm{Si}_{2} \mathrm{O}_{6} \\
\text { (Ferrosilita) }\end{array}$ & $\begin{array}{c}\mathrm{SiO}_{2} \\
\text { (Quartzo) }\end{array}$ & \\
\hline & \multicolumn{2}{|c|}{$33-28$} & \multicolumn{2}{|c|}{$33-26$} & \multicolumn{2}{|c|}{$15-8$} & $11-8$ & $4-2$ & $17-15$ \\
\hline \multirow{3}{*}{ 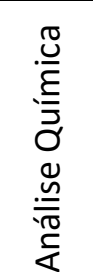 } & \multicolumn{9}{|c|}{ Elementos / Compostos (\%) } \\
\hline & $\mathrm{Mn}$ & $\mathrm{Fe}$ & $\mathrm{SiO}_{2}$ & & & $\mathrm{~A}_{12} \mathrm{O}$ & $\mathrm{CaO}$ & $\mathrm{MgO}$ & $\mathrm{TiO}_{2}$ \\
\hline & 28,44 & 4,46 & 24,59 & \multicolumn{2}{|c|}{0,092} & 7,77 & 5,100 & 1,790 & 0,280 \\
\hline
\end{tabular}

\subsection{Redução de minérios de manganês em fornos elétricos a arco}

A produção comercial de ferroligas de manganês ocorre pela redução carbotérmica de óxidos de manganês. A mistura de matérias primas alimentadas no forno de redução ao atingir temperaturas na ordem de $1200^{\circ} \mathrm{C}$ se funde, com exceção dos redutores. A liga metálica e a escória depositam-se no cadinho e durante o vazamento do forno são separadas, por diferença de densidade, em um dispositivo chamado skimmer OLSEN et al [1].

A figura 2 exibe as principais reações químicas que ocorrem no forno elétrico de redução. No topo do forno acontece a eliminação da umidade contida nas matérias primas e a redução do $\mathrm{MnO}_{2}$ para $\mathrm{Mn}_{2} \mathrm{O}_{3}$. Na zona intermediária ocorre a redução da magnetita $\left(\mathrm{Fe}_{3} \mathrm{O}_{4}\right)$ em ferro $(\mathrm{Fe})$ e a decomposição do carbonato de cálcio $\left(\mathrm{CaCO}_{3}\right)$, o qual forma o óxido de cálcio $(\mathrm{CaO})$ e o gás redutor monóxido de carbono (CO) que irá ascender no interior do forno e promover a redução indireta dos óxidos de manganês e de ferro. Na zona inferior do forno predomina a fase líquida, essa região ocorre a redução direta do óxido de manganês $(\mathrm{MnO})$ e do quartzo $\left(\mathrm{SiO}_{2}\right)$ pelo carbono OLSEN et al [1].

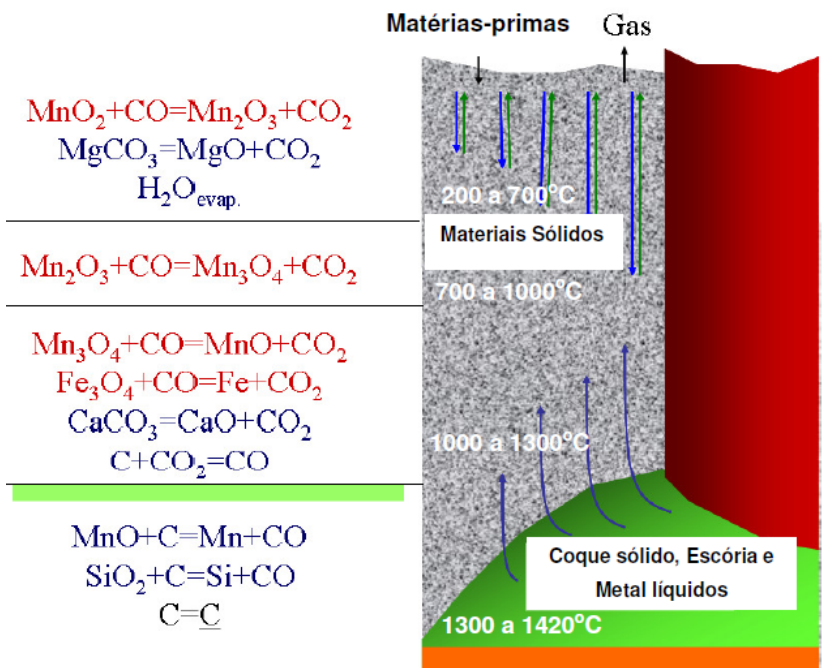

Figura 2. Principais reações por zonas no forno elétrico de redução (Adaptado de OLSEN et al)[1]. 


\section{MATERIAIS E MÉTODOS}

A figura 3 exibe o fluxograma esquemático da metodologia adotada para realização do trabalho e elaboração do artigo. Os dados do consumo de energia mensal e do balanço de massa dos minérios utilizados foram coletados do sistema de gestão de produção (SGP). Os históricos de dados foram obtidos de dois fornos elétricos de redução (Forno 1 e Forno 2), no intervalo de janeiro de 2011 a dezembro de 2012. Esse período foi escolhido pelo fato de abranger campanhas de produção de um único tipo de liga.

Os dados dos históricos de processo foram reorganizados em ordem crescente do valor de consumo específico de energia, com o intuito de facilitar a identificação e análise de correlações. Portanto, os gráficos dos resultados mostrados na figura $4 \mathrm{e}$ 5 não estão organizados em ordem cronológica, mas sim no aumento do consumo de energia.

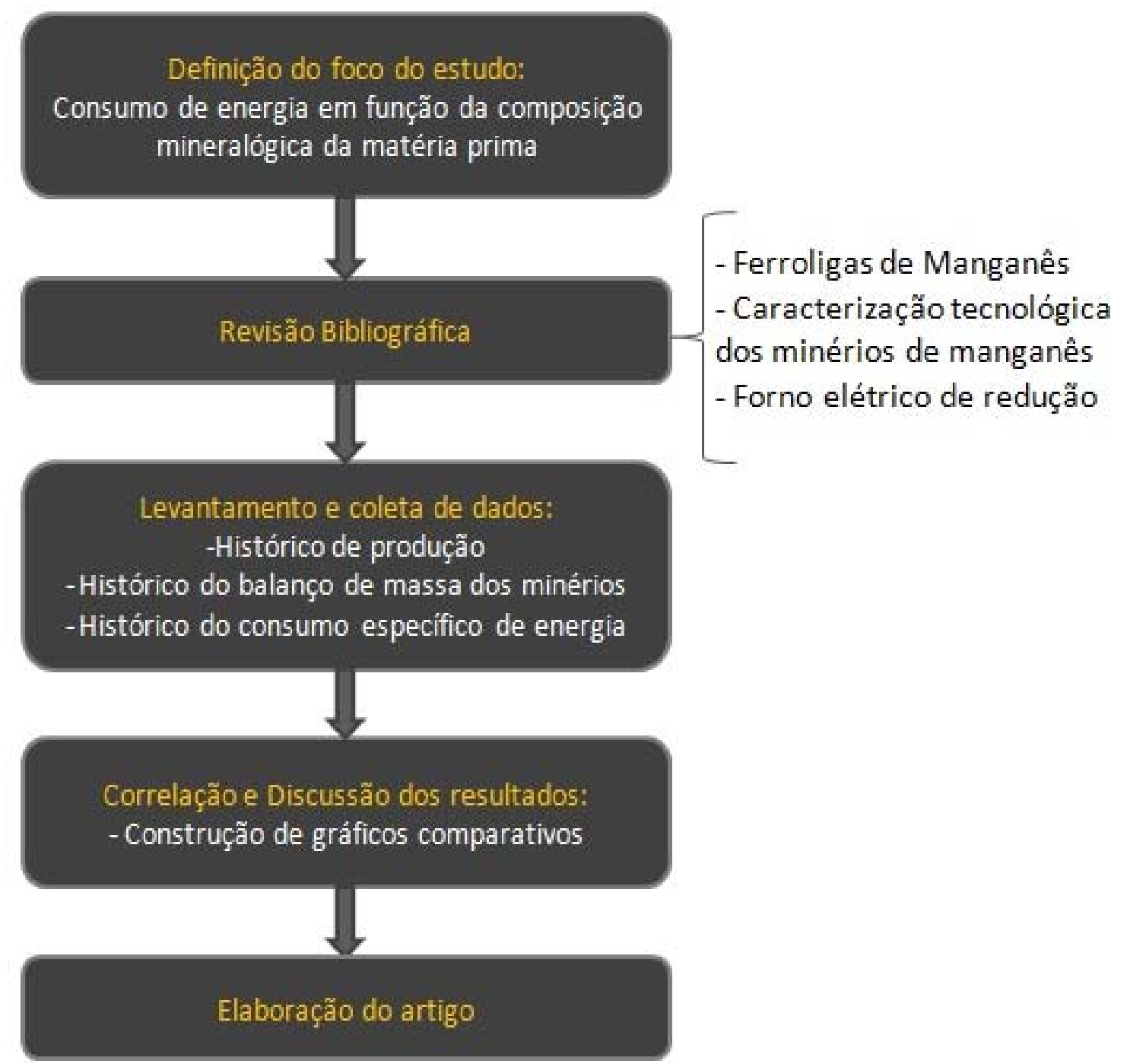

Figura 3. Fluxograma da metodologia empregada para elaboração do trabalho 


\section{RESULTADOS E DISCUSSÃO}

Nas figuras 4 e 5 estão apresentados os resultados da correlação dos históricos de produção e do consumo específico de energia do forno 1 e do forno 2 . Em ambos os fornos, o aumento da quantidade do minério de manganês Sílico Carbonatado (Morro da Mina) na carga metálica de alimentação promove o crescimento do consumo de energia no processo de produção. A título de exemplo, o consumo de energia para o período de produção de junho de 2011 no forno $1 \mathrm{com}$ proporção de $50 \%$ Sílico Carbonatado, 24\% Urucum e 26\% Carajás foi de 4,023 MWh/t. Enquanto que, no período de fevereiro de 2012 para o mesmo forno com proporção de $90 \%$ Sílico Carbonatado, $8 \%$ Urucum e $2 \%$ de Carajás foi de 4,750 MWh/t. Essa mudança no balanço de massa da carga metálica representou um aumento de $18 \%$ no consumo de energia específico.

A análise da variação do consumo de energia considerando apenas as proporções dos minérios de Urucum e Carajás não é tão clara como do minério Sílico Carbonatado. Porém, recorrendo a revisão bibliográfica é possível determinar, entre os dois minérios, o que possui o melhor comportamento de pré-redução.

Faria (2011) [2] realizou testes de pré redução de minérios de manganês granulados, dentre estes os minérios abordados neste trabalho, destacando que este termo é aplicado porque não há a formação de manganês metálico no estado sólido, como pode ser observado em diagramas de estabilidade do sistema Mn-CO. Nos ensaios realizados for Faria [2] foi possível determinar o minério que possui o melhor comportamento na pré-redução, analisando quatro parâmetros proposto pelo mesmo (Eficência de Pré-Redução (EP); Velocidade Instãntanea de Pré-Redução (VIP); Velocidade Média de Pré-Redução (VMP) e o Fator de Pré-Redução (FP)), O minério de manganês que apresentou o melhor desempenho na redução foi o minério de Azul ou Carajás.

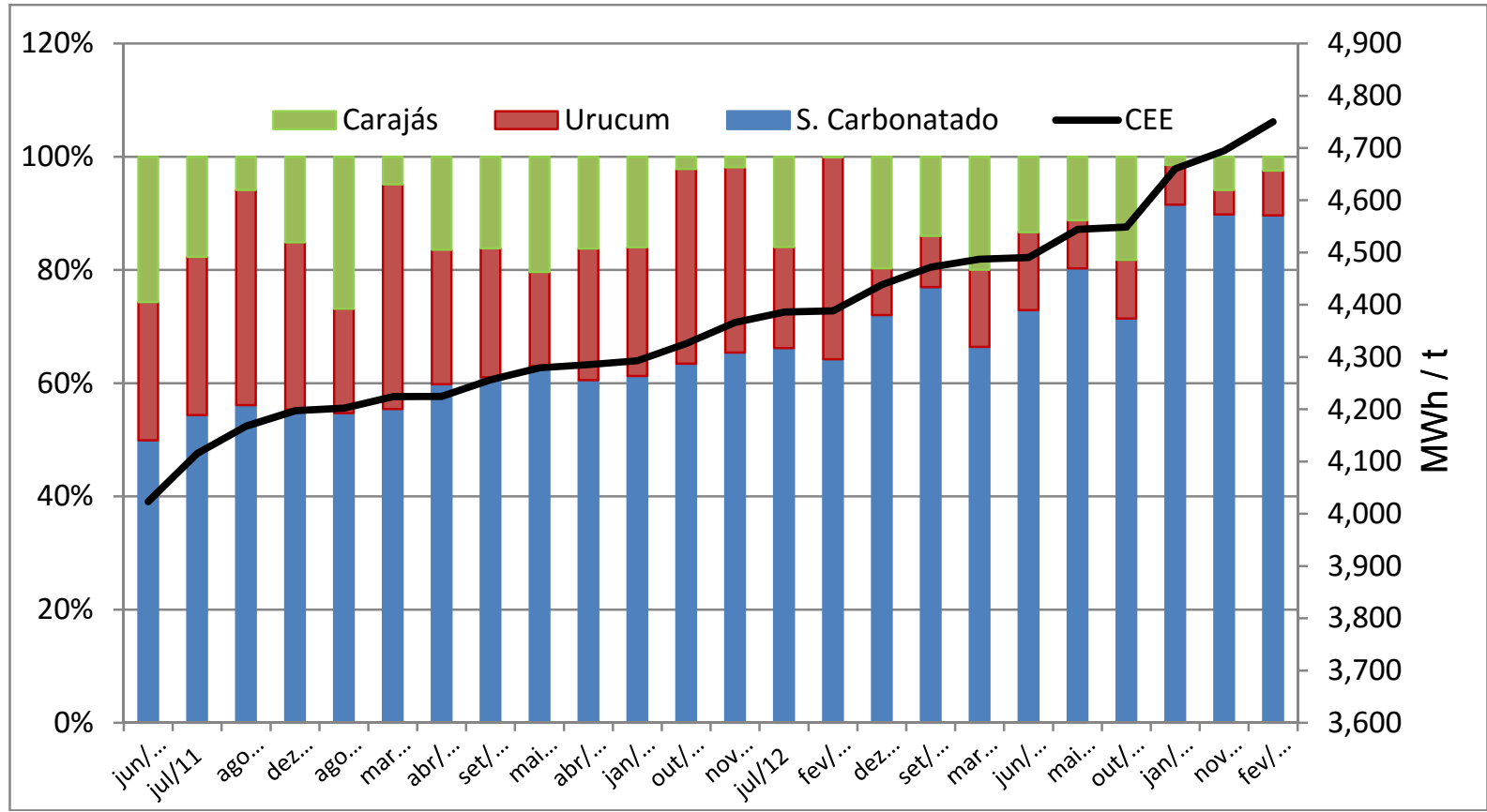

Figura 4. Comparativo entre as diferentes proporções de minérios na carga metálica e o consumo específico de energia do forno $1 .{ }^{*} \mathrm{CEE}=$ Consumo de Energia Específico 


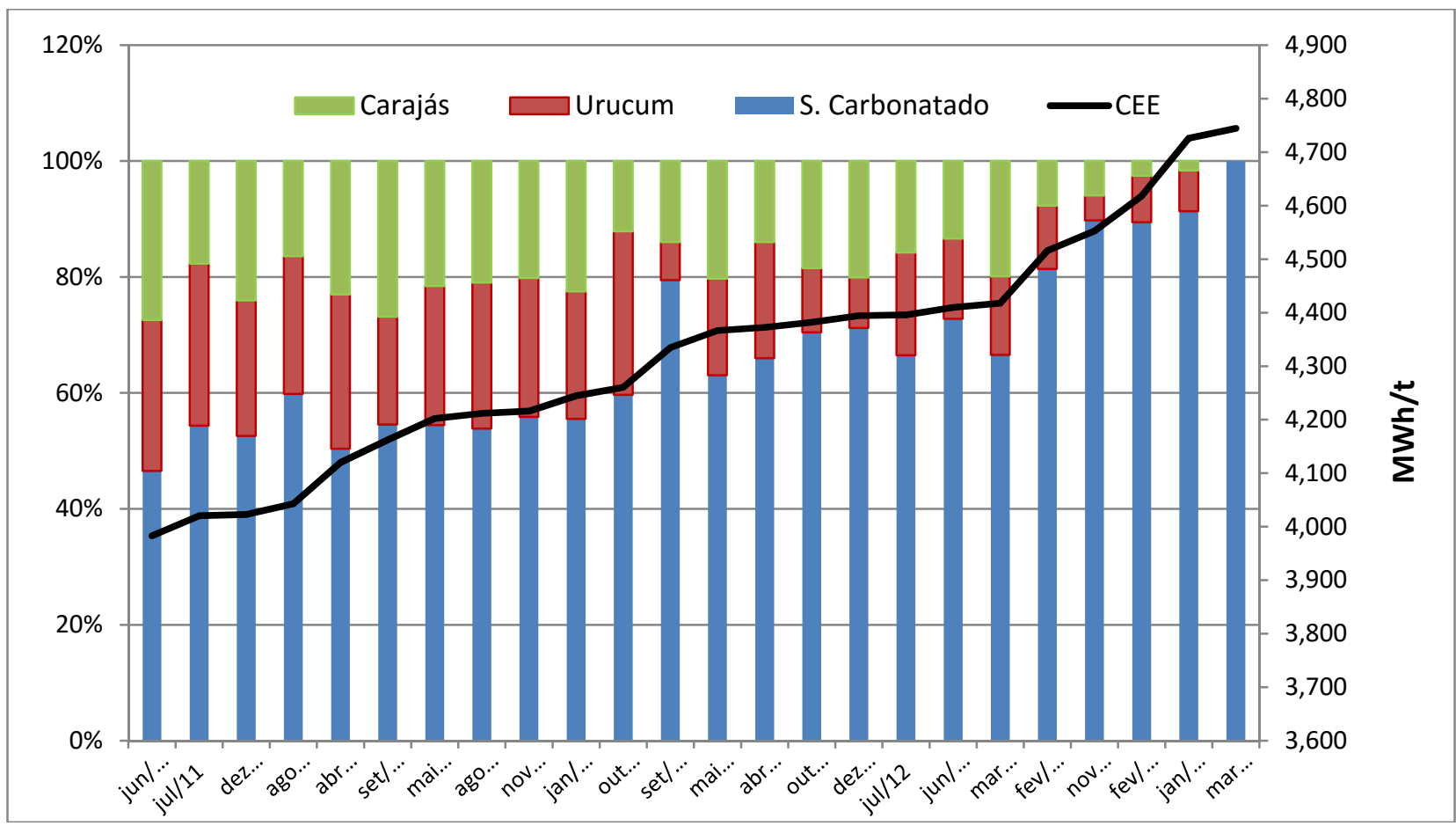

Figura 5. Comparativo entre as diferentes proporções de minérios na carga metálica e o consumo específico de energia do forno 2. ${ }^{*} \mathrm{CEE}=$ Consumo de Energia Específico

\section{CONCLUSÕES}

1. Os melhores resultados do consumo de energia específico nos fornos $1 \mathrm{e}$ 2 foram obtidos, no período analisado, quando se tem menores quantidades do minério Sílico Carbonatado (Morro da Mina) na alimentação da carga metálica.

2. Por meio da revisão bibliográfica do trabalho realizado por Faria [2] e pelos gráficos obtidos nesse presente trabalho, recomenda-se uma ordem a priorizar na alimentação dos minérios como carga metálica. Essa ordem, segue: Minério de manganês de Carajás, Minério de manganês de Urucum e, por último, minério Sílico Carbonatado.

3. A energia envolvida nos processos metalúrgicos é um dos fatores determinantes da produção de um produto, podendo viabilizar ou não sua extração. Portanto, a seleção de parâmetros, indicadores e de matérias primas com melhor performance no processo promove a otimização da operação, prolongando a viabilidade econômica da atividade.

\section{Agradecimentos}

Á Vale e a Faculdade Santa Rita, pela colaboração na elaboração do trabalho.

\section{REFERÊNCIAS}

1 OLSEN, S. E.; Tangstad, M.; Lindstad, T. Production of Manganese Ferroalloys.

Trondheim: Tair Academic Press, 2007.

2 Faria, G. L. Estudo Geometalúrgico de Granulados e Pelota de Minério de Manganês. Programa de Pós-Graduação em Engenharia de Materiais REDEMAT - UFOP (Teste de Do Ouro Preto). Ouro Preto, Minas Gerais, Brasil, 2011.

3 VALE. Relatório técnico interno da Vale. Ouro Preto, Minas Gerais, Brasil, 2015. 